\title{
CHARACTER STRENGTHS, SOCIODEMOGRAPHIC CHARACTERISTICS, AND LIFE SATISFACTION IN MEXICAN STUDENTS
}

\section{FORTALEZAS DEL CARÁCTER, CARACTERÍSTICAS SOCIODEMOGRÁFICAS Y SATISFACCIÓN CON LA VIDA EN ESTUDIANTES MEXICANOS}

\author{
NORMA Alicia RUVAlCABA-ROMERO ${ }^{1}$, \\ JULIA GALLEGOS-GUAJARDO ${ }^{2}$, \\ LAURA N. ALFARO-BERACOECHEA ${ }^{1}$, AND \\ GABRIELA OROZCO-SOLÍS ${ }^{1}$
}

Cómo referenciar este artículo/How to reference this article:

Ruvalcaba-Romero N. A., Gallegos-Guajardo, J., Alfaro-Beracoechea, L. N., \& Orozco-Solís, G. (2018). Character strengths, sociodemographic characteristics, and life satisfaction in Mexican students [Fortalezas del carácter, características sociodemográficas y satisfacción con la vida en estudiantes mexicanos]. Acción Psicológica, 15(2), 95-106. https://doi.org/10.5944/ap.15.2.22207

\begin{abstract}
The main purpose of this study was to identify the existing relationship between character strengths and life satisfaction, as well as some sociodemographic aspects
\end{abstract}

related to gender differences. Both the Virtue and Strength Inventory (IVYF; Cosentino \& Castro, 2008) and the Satisfaction with Life Scale (SWLS; Diener, Emmons, Larsen \& Griffin, 1985) were administered to 343 undergraduate students whose primary major of study pertained to health professions. Results indicated that for

Correspondencia Norma Alicia Ruvalcaba-Romero. Universidad de Guadalajara, México. Email: nruval@hotmail.com

ORCID: Norma Alicia Ruvalcaba-Romero (http://orcid.org/0000-0001-9209-8751), Julia Gallegos-Guajardo (http://orcid.org/0000-0001-5678-2353), Laura N. Alfaro-Beracoechea (http://orcid.org/0000-0002-9857-7339) y Gabriela Orozco-Solís (http://orcid.org/0000-0002-0648-8233).

${ }^{1}$ Universidad de Guadalajara, México.

${ }^{2}$ Universidad de Monterrey, México.

Retrieved: May 3, 2018. Aceptado: July 25, 2018. 
women, love and gratitude are the strengths that explained $21.3 \%$ of the variance regarding satisfaction with life, while love and social intelligence predicted $44.5 \%$ of life satisfaction for men. Results are discussed under the light of cultural differences.

Keywords: Character strengths; Life satisfaction; Gender differences; Mexican adults.

\section{Introduction}

Positive psychology offers a way to go beyond pathology prevention by focusing on the promotion of mental health (Kobau et al., 2011). The work of positive psychology is orientated towards helping individuals function at their optimal state, and it is encouraged through actions that cultivate positive emotions and the improvement of skills, resources and psychological strengths (Kobau et al., 2011; Martínez-Marti, 2006; Seligman, Steen, Park, \& Peterson, 2005). The purpose of this epistemological proposal is the overall improvement of all individuals and communities by simultaneously seeking enhancement of wellbeing and quality of life and preventing the development of physical and mental health problems (Ferragut, Blanca, \& Ortiz-Tallo, 2014; Kobau et al., 2011).

Within its developmental process, positive psychology has paved way for a wide field of research with the following four focus areas: subjective, individual, institutional, and collective -in groups- (Consentino, 2009; Kobau et al., 2011). The subjective area is focused on the study of satisfaction, happiness, gratitude, and experiences that foster wellbeing; the individual area focuses on positive character traits such as values, talent, and human strengths; the institutional area's focus is on the identification of organizations that promote the development of skills and positive subjective experiences; and finally, in the collective/group area, the focus is on positive relationships (Seligman \& Csikszentmihalyi, 2000).

The study of positive personality traits has been a prominent topic that has gathered major attention in the last few years, as it diverges from the traditional focus on negative indicators and risk factors (Consentino, 2009).
These character traits include a variety of predispositions, such as creativity, courage, and optimism, which help an individual to interact positively with his or her environment. Peterson and Seligman (2004) were the authors who strongly promoted the study of good character from the beginning of positive psychology, which is built with different components and levels of complexity. Virtues are central characteristics of personality, which have been valued positively by thinkers and religious figures throughout history (Dahlsgaard, Peterson, \& Seligman, 2005; Peterson \& Seligman, 2004). Strengths, placed in the next level of the hierarchy, are defined as psychological characteristics that make up and manifest basic virtues of the human being (Peterson \& Seligman, 2004). Situational themes, found in the most basic level, are specific habits that take place during the practice of certain strengths (Cosentino, 2009).

Peterson and Seligman (2004) developed a classification for human strengths and virtues which seeks to unify the existing personality classifications in diagnostic manuals and provide a scientific tool to evaluate interventions designed within positive psychology. Seeking to identify universal values (common human virtues among different cultures, theories, and authors), Peterson and Seligman created this classification from the analysis of different cultures and religions. The authors proposed the existence of 24 global strengths in the following six virtues: wisdom and knowledge (which include creativity, curiosity, openmindedness, love of learning, and perspective); courage (consisting of bravery, persistence, integrity, and zest); humanity (includes love, kindness, and social intelligence); justice (citizenship, fairness, and leadership); temperance (involves forgiveness, humility/modesty, prudence, and self-regulation); and transcendence (a group made up of appreciation of beauty and excellence, gratitude, hope, humor, and spirituality).

Character strengths have been associated with an increase in positive emotions, the propensity to compromise, the development of enriching relationships, the motivation to reach personal goals, and a feeling of living a meaningful and fulfilling life (Eguiluz \& Plasencia, 2014; Ferragut et al., 2014; Seligman, 2011). In this way, human strengths are considered psychologically satisfactory, making the relationship between character strengths and life satisfac- 
tion, another main subject of this theoretical proposal, evident as a factor of wellbeing (Castro \& Cosentino, 2016; Seligman, 2011).

One factor that influences differences in character strengths is gender, as noted by the observation that females were more likely to display love, gratefulness, and solidarity, while males usually demonstrated more selfregulation and bravery (Castro \& Cosentino, 2016; Buschor, Proyer, \& Ruch 2013; Shimai, Otake, Park, Peterson, \& Seligman, 2006). However, other studies have reported higher scores for men in zest, prudence, selfregulation, and optimism (Reyes \& Ferragut, 2016), and higher scores for women in appreciation of beauty, kindness, love, and gratitude (Heintz, Kramm, \& Ruch, 2019). Taking these differences into account, gender might be a variable influencing the variability in the association between character strengths and other factors.

\section{Character strengths and life satisfaction}

The interaction between character strengths and satisfaction with life is an area that has been deeply studied in several population sectors, due to the psychologically enriching character of human strengths (Eguiluz \& Plasencia, 2014). Life satisfaction is defined as the assessment a person places upon his or her life, resulting in the balance they perceive between their accomplishments and initial expectations (Pavot \& Diener, 1993).

The first research conducted on this subject discovered that among adults of the United States, the character strengths of hope, vitality, love, gratitude, and curiosity were strongly associated with a greater satisfaction with life (Park, Peterson, \& Seligman, 2004). Meanwhile, character strengths such as modesty, appreciation of beauty, creativity, perspective, and love for learning, were weakly related to this contentment with life. Following initial works, the study of the relationship between human strengths and satisfaction with life became a targeted research area in myriad places around the world.

In studies conducted with adults from countries like Croatia, Germany, Slovenia, Switzerland, and the United States, it is again found that kindness, hope, vitality, love, gratitude, optimism, and curiosity appear to be the character strengths that have the strongest correlation with life satisfaction (e.g., Boehm, Lyubomirsky, \& Sheldon, 2011; Brdar \& Kashdan, 2010; Buchanan \& Bardi, 2010; Buschor et al., 2013; Gradišek, 2012; Peterson et al., 2007; Proyer, Gander, Wyss, \& Ruch, 2011). Nevertheless, some slight differences were observed in different studies. For example, in studies of German-speaking adults living in Switzerland, it is reported that the strengths with a stronger relationship with satisfaction of life were hope, vitality, love, social intelligence, and perseverance (Martínez \& Ruch, 2014). Furthermore, in Peterson, Ruch, Beermann, Park, and Seligman (2007) work, where adults from the United States and Switzerland participated, it is mentioned that for Americans, gratitude is the factor with the highest predictive value of life satisfaction, while for the Swiss, perseverance appeared to occupy this position.

Similarly, Gradišek (2012) mentioned in a study conducted with school teachers that humor is also a strength heavily related to life satisfaction. On the other hand, it was found that for young adults, hope predicted higher satisfaction with life, in comparison to samples from adults, in which love and citizenship were found to be the most significant predictors (Isaacowitz, Vaillant, \& Seligman, 2003).

In Latin America, there are only a few studies that have studied this relationship. Results from a study conducted in Colombia conveyed that the strengths that hold the highest association with satisfaction of life were vitality, gratitude, hope, perseverance, and love (Porto \& Fonseca, 2016). As for Mexico, Eguiluz and Plasencia (2014) reported that the strengths that showed the strongest correlation with life satisfaction were love, appreciation for beauty, gratitude, and hope. Meanwhile, the strengths that exhibited a weaker association with life satisfaction were modesty, self-regulation, love for knowledge, perseverance, prudence, and forgiveness.

Another example which demonstrated cultural differences for Latin America is the study carried out by Vela, Scott, Ikonompoulos, González, and Rodríguez (2017). This study explored the role of character strengths in Mexican-American students. Results revealed that op- 
timism, grit, and gratitude were significant predictors of life satisfaction.

As aforementioned, there are significant differences in the character strengths associated with life satisfaction among populations. One factor that may explain this disparity relates to the cultural differences that exist between the countries where this relationship has been examined. According to some authors, one cultural element that influences the orientation to happiness and life satisfaction is the perspective about the participation of the individual in the social context (Ahuvia, 2001; Park \& Huebner, 2005; Park, Peterson, \& Ruch, 2009). As mentioned by Ahuvia (2001), countries with higher levels of socioeconomic development tend to favor a more individualistic posture, while developing countries tend to promote a more collectivist approach. Hofstede (2011) defines individualistic cultures as those with loose ties between the individuals that make up the society, where a person is expected to satisfy his or her own needs and pursuit personal happiness above social obligations. On the contrary, according to the author, collectivist cultures integrate individuals into strong social groups since birth, where happiness and life satisfaction is achieved through the sense of meaning and belonging.

\section{Current study}

As literature demonstrates, the relationship between character strengths and satisfaction with life is a subject that has been profoundly studied in various countries, mainly due to the influence it has on mental health and the optimal state of wellbeing in individuals. Nevertheless, despite the relevance that this interaction has regarding the promotion of health, there have only been a few studies that have explored this relationship in Latin America, particularly in Mexico and especially at the predictive level. Likewise, the relationship based on gender differences has not been explored yet. Therefore, this study has adopted the goal of exploring these areas in greater detail. Considering that Mexico is a collectivist country, it was hypothesized that the character strengths related to the virtues of humanity and transcendence are the ones that cause a higher impact on satisfaction with life.

\section{Method}

\section{Participants}

For the current study, a convenience sample was used. It was composed of 343 undergraduate students pursuing a bachelor's degree in a variety of health-related areas of study, with an age range between 17 and 30 years old $(\mathrm{M}=20.91, \mathrm{SD}=2.95)$. The group consisted of $30 \%$ males and $70 \%$ females.

\section{Instruments}

Sociodemographic form. Sociodemographic data was evaluated through a form in which age, occupation, gender, area of residence, marital status, and education level were taken into account.

Virtues and Strengths Inventory (IVyF; Cosentino \& Castro, 2008). This measure is an inventory that was developed to evaluate six virtues and 24 character strengths according to classification made by Peterson and Seligman (2004). This measure includes 24 items that describe a person that exhibits the specific characteristics that pertain to the strength to be evaluated. This measure simultaneously describes a person with a lack of those characteristics. For example, an individual who encompasses the strength of gratitude is described as the following: "I see myself as a lucky person because I believe I have been blessed in life; every day I have a profound feeling of gratitude. Furthermore, I express my gratitude with the people who are good to me." For the same strength, the corresponding description for an individual who lacks the quality of gratitude is as follows: "There are few things for which I feel grateful, and I don't feel the need to say thank you or express my gratitude with the people that are good to me". The response options are comprised of a 5-point Likert scale that ranges from option 1 ("I am very similar to person 1") to option 5 ("I am very similar to person 2"). This instrument has proven to have adequate psychometric properties evaluated through test-retest stability, exhibiting correlation coefficients for each response that oscillate between .73 and .92 (Cosentino, 2009). 
Satisfaction with Life Scale (SWLS; Diener et al., 1985). This measure is a unifactorial scale with five items and seven Likert type answer choices ranging from 1 ("Strongly disagree") to 7 ("Strongly agree"). The instrument was designed to measure global cognitive judgments of satisfaction with one's life. Some sample items include item 1 ("In most ways my life is close to my ideal") and item 5 ("If I could live my life over, I would change almost nothing"). This measure usually requires only about a couple of minutes of a respondent's time. It has reported adequate psychometric properties (Padrós, Gutiérrez, \& Medina, 2015). A Cronbach's alpha of $\alpha=.722$ was obtained in this study.

\section{Procedure}

The measures were administered during an ordinary school schedule and on a written paper-and-pencil format.
The measures were collected in the classrooms with prior informed consent. Afterwards, data was captured and analyzed using the SPSS software v. 21. Descriptive statistics were calculated, and Pearson correlations and linear regression analyses were performed.

\section{Results}

The descriptive results for each of the variables in this study divided by gender are found in Table 1. For both genders, self-regulation reported the lowest scores.

With the purpose of identifying the relationship between character strengths and some sociodemographic variables, Pearson correlation coefficients were calculated. Results are reported in Table 2. As it can be ob-

Table 1

Satisfaction with life and character strengths descriptive statistics (in ascending order).

\begin{tabular}{|c|c|c|c|c|c|c|c|c|c|}
\hline & \multicolumn{4}{|c|}{ Male } & & \multicolumn{4}{|c|}{ Female } \\
\hline & Mean & S.D. & Min & Max & & Mean & S.D. & Min & Max \\
\hline Life Satisfaction & 5.15 & .984 & 2.4 & 7 & Life Satisfaction & 5.36 & .926 & 2 & 7 \\
\hline Self-regulation & 3.05 & .957 & 1 & 5 & Self-regulation & 3.02 & 1.069 & 1 & 5 \\
\hline Spirituality & 3.14 & 1.295 & 1 & 5 & Citizenship & 3.35 & .909 & 1 & 5 \\
\hline Love & 3.20 & 1.239 & 1 & 5 & Humility & 3.45 & .864 & 1 & 5 \\
\hline Persistence & 3.21 & 1.008 & 1 & 5 & Forgiveness & 3.49 & .907 & 1 & 5 \\
\hline Humility & 3.28 & .946 & 1 & 5 & Spirituality & 3.52 & 1.095 & 1 & 5 \\
\hline Citizenship & 3.31 & 1.002 & 1 & 5 & Love of learning & 3.56 & .901 & 1 & 5 \\
\hline Forgiveness & 3.32 & .942 & 1 & 5 & Humor & 3.58 & .905 & 1 & 5 \\
\hline Humor & 3.39 & 1.048 & 1 & 5 & Hope & 3.58 & 1.073 & 1 & 5 \\
\hline Love of learning & 3.44 & .944 & 1 & 5 & Bravery & 3.70 & .908 & 1 & 5 \\
\hline Hope & 3.49 & .969 & 1 & 5 & Persistence & 3.72 & 1.033 & 1 & 5 \\
\hline Prudence & 3.60 & .876 & 1 & 5 & Love & 3.74 & 1.005 & 1 & 5 \\
\hline Zest & 3.62 & .845 & 1 & 5 & Social Intelligence & 3.81 & .927 & 1 & 5 \\
\hline Bravery & 3.72 & .922 & 1 & 5 & Prudence & 3.82 & .838 & 1 & 5 \\
\hline Fairness & 3.75 & 1.067 & 1 & 5 & Creativity & 3.83 & .911 & 1 & 5 \\
\hline Leadership & 3.76 & .889 & 1 & 5 & Zest & 3.89 & .832 & 1 & 5 \\
\hline Social Intelligence & 3.77 & 1.136 & 1 & 5 & Leadership & 3.89 & 1.037 & 1 & 5 \\
\hline Appreciation of beauty & 3.79 & .891 & 2 & 5 & Appreciation of beauty & 3.98 & .905 & 1 & 5 \\
\hline Open mindedness & 3.79 & .988 & 2 & 5 & Open mindedness & 4.01 & .923 & 1 & 5 \\
\hline Integrity & 3.81 & 1.089 & 1 & 5 & Curiosity & 4.05 & .851 & 1 & 5 \\
\hline Gratitude & 3.82 & .978 & 1 & 5 & Fairness & 4.08 & .918 & 1 & 5 \\
\hline Kindness & 3.91 & .922 & 1 & 5 & Perspective & 4.08 & .729 & 2 & 5 \\
\hline Curiosity & 4.00 & .888 & 1 & 5 & Gratitude & 4.13 & .849 & 1 & 5 \\
\hline Creativity & 4.01 & .904 & 1 & 5 & Integrity & 4.19 & .795 & 1 & 5 \\
\hline Perspective & 4.09 & .830 & 2 & 5 & Kindness & 4.23 & .705 & 2 & 5 \\
\hline
\end{tabular}


served, only the variable of social intelligence showed a statistically significant correlation with both age and educational level. Spirituality and Integrity reported a weak but positive and statistically significant correlation with age, and in the same way, Citizenship with educational level. On the other hand, Curiosity reported a negative and statistically significant correlation with education level.

Table 2.

Statistically significant correlations with the variables of age and educational level.

\begin{tabular}{lcc}
\hline Strengths & Age & Education Level \\
\hline Spirituality & $.107^{*}$ & \\
Integrity & $.114^{*}$ & \\
Social Intelligence & $.157^{* *}$ & $.108^{*}$ \\
Citizenship & & $.108^{*}$ \\
Curiosity & $-.180^{* *}$ \\
\hline Note. ${ }^{*} p<.05^{* *} p<.01$. &
\end{tabular}

Aiming to identify the character strengths with the highest association with life satisfaction, Pearson correlations were also performed, and the results are reported in An, which includes the correlation coefficients of men on the top portion and women on the bottom portion (see Appendix 3).

Table 3.

Linear regression analysis of character strengths on satisfaction with life (Male).

\begin{tabular}{lcccc}
\hline & $\mathbf{R}^{\mathbf{2}}$ & $\mathbf{F}$ & $\boldsymbol{\beta}$ & $\boldsymbol{p}$ \\
\hline Model 1 & 0.445 & $4.314^{* * *}$ & & \\
Social Intelligence & & & $.405^{* * *}$ & .001 \\
Love & & & $.293^{*}$ & .011 \\
Forgiveness & & & .187 & .117 \\
Humor & & & .141 & .212 \\
Kindness & & & -124 & .321 \\
Gratitude & & .086 & .496 \\
Fairness & & -.080 & .505 \\
Creativity & & & .060 & .559 \\
Zest & & .060 & .592 \\
Citizenship & & -.058 & .583 \\
Leadership & & -.049 & .653 \\
Hope & & .028 & .805 \\
Spirituality & & .001 & .991 \\
\hline Note. ${ }^{*} p<.05,{ }^{* *} p<.01 .{ }^{* * *} p<.00$. & &
\end{tabular}

In order to explore the predictive level of each of the character strengths on life satisfaction, variables with significant statistical relevance were entered into a linear regression analysis. Results are reported in Tables 3 and 4. It was be observed that for women, the only variables that remained statistically significant were gratitude and love; for men, love and social intelligence reported the highest predictive levels for life satisfaction.

Table 4.

Linear regression analysis of character strengths on satisfaction with life (Female).

\begin{tabular}{lllll}
\hline & $\mathbf{R}^{\mathbf{2}}$ & $\mathbf{F}$ & $\boldsymbol{\beta}$ & $\mathbf{p}$ \\
\hline Model 1 & 0.213 & $4.475^{* * *}$ & & \\
Gratitude & & & $.172^{*}$ & .017 \\
Love & & & $.152^{*}$ & .024 \\
Curiosity & & & .136 & .068 \\
Integrity & & .127 & .077 \\
Spirituality & & .091 & .181 \\
Self-regulation & & & .065 & .334 \\
Hope & & .052 & .453 \\
Perspective & & .039 & .589 \\
Social Intelligence & & .032 & .648 \\
Leadership & & .018 & .797 \\
Zest & & .004 & .955 \\
Persistence & & .003 & .966 \\
\hline Note. ${ }^{*} p<.05,{ }^{* *} p<.01 .{ }^{* * *} p<.00$. & & &
\end{tabular}

The analysis that explored how character strengths predict life satisfaction revealed that social intelligence $(\mathrm{b}=.40)$ and love $(\mathrm{b}=.29)$ predicted $44 \%$ of the variance of satisfaction with life in men, while gratitude $(b=.17)$ and love $(b=.15)$ predicted $21 \%$ of the variance of satisfaction in life in women. The remaining character strengths lost significance in both models.

\section{Discussion}

The purpose of this study was to explore the relationship between character strengths and life satisfaction in Mexican undergraduate students and to further examine gender differences. According to the results presented, it is important to notice that the magnitudes of the significant correlations between satisfaction with life and character strengths were higher in men than in women. The stronger 
correlations between satisfaction with life and character strengths in women were found in gratitude $(r=.32)$, integrity $(r=.26)$, love $(r=.24)$, curiosity $(r=.24)$, and zest $(r=.22)$, while in men, the stronger correlations with life satisfaction were found in social intelligence $(r=.50)$, love $(r=.43)$, hope $(r=.35)$, humor $(r=.33)$, and forgiveness $(r=.30)$. These results contradict the findings of other authors (Castro \& Cosentino, 2016; Buschor et al., 2013; Shimai et al., 2006), and although the size of the sample may be a factor to consider, it could also reveal that in the current sample, character strengths may have more significant weight in life satisfaction for men than for women.

According to this sample, the results suggest that the virtues that predict satisfaction with life are those related with humanity and transcendence, as was hypothesized. It was observed that people give special importance to strengths related to interpersonal relationships that may enhance social support. These results could be related with the idea of Ahuvia (2001), who stated that collectivist characteristics in developing countries usually give special importance to the social group and social support as elements that promote life satisfaction.

On the other hand, satisfaction with life implies recognition of whether good living conditions and personal goals have been achieved. Therefore, in women, gratitude as the recognition and appreciation for what has been received and achieved is consistent with those who experience life satisfaction and well-being (Lambert, Fincham, Stillman, \& Dean, 2009).

When comparing the results to other studies (i.e., Park et al., 2004; Peterson et al., 2007), there is an evident similarity in which the character strengths of love and gratitude were also the most related to life satisfaction, while the love for knowledge was the least related construct. Nevertheless, in both analysis of correlations and linear regression, social intelligence, defined as the ability to understand and manage emotions in relation to others (Peterson \& Seligman, 2004), was found to also be strongly related in our male sample, revealing and reaffirming the idea that men place particular importance on interactions with other individuals when evaluating the quality of their lives.
Social intelligence and love also scored highly and positively with life satisfaction in the study of MartínezMartí and Ruch (2014), which is similar to the results reported in the present study. Other character strengths that were associated with life satisfaction within this study sample were hope, vitality, and perseverance, reporting positive relationships for both men and women.

When comparing the results of the present study with studies that have been conducted in Latin America and Mexico, similarities in the emphasis of love and gratitude as character strengths highly related with life satisfaction were found (Porto \& Fonseca, 2016; Vela et al., 2017). The authors also found associations of life satisfaction with vitality, hope, and perseverance; however, in the present study, these strengths which showed a positive and significant correlation did not result to be significant in the linear regression analysis that was conducted. Furthermore, these strengths did not reveal a predictive value on life satisfaction. A similar study by Eguiluz and Plasencia (2014) concluded that appreciation for beauty maintained a strong positive correlation with satisfaction with life, but in the present study, it did not hold a predictive value nor a significant association.

Taking into account that the current sample exclusively contains only undergraduate students, the results of this study showed that age has been positively correlated with the development the character strengths of social intelligence, integrity, and spirituality. Additionally, educational level reported to be positively associated with social intelligence and citizenship, but held a negative association with curiosity. These results are different from those reported in the study of Isaacowitz et al. (2003), which explored the predictive value of hope on life satisfaction with young adults from the United States. Unlike the study aforementioned, hope did not result as a significant factor in this regression analysis, while love did have a predictive value for the current sample. These results shed light on the possible cultural differences that may influence satisfaction with life in Mexican young adults.

Additionally, the findings of the present study are different from those found in the first approximations to the construct, where all the character strengths were related to life satisfaction (Park et al., 2004). Thus, it is possible that 
there may be differences in the weight given to the character strengths related to interpersonal relationships and social support in Mexican culture. Cultural differences regarding the effect of character strengths over satisfaction with life have been approached in the study of Boehm et al. (2011), who concluded that individualist cultures enhance life satisfaction through personal achievement, while collectivist cultures are oriented to avoid self-focused gratifications.

It is important to interpret these findings taking into account some limitations encountered in the current study, such as the number of participants in the sample and their specific characteristics. Future research should increase a broader sample in terms of age, career paths, and socioeconomic level in order to determine if there are existing differences based on occupational status. Longitudinal studies are also suggested to explore the differences of these relationships over time.

In conclusion, the current study reveal that some character strengths, particularly love and social intelligence as part of the humanity virtue, and the strength of gratitude, from the transcendence virtue, contribute positively to life satisfaction. Future research should study other dimensions of subjective and psychological well-being such as the experience of positive emotions, self-esteem, and mastery of the environment in accordance to character strengths and virtues across all age groups within the Mexican population.

\section{References}

Ahuvia, A. (2002). Individualism/collectivism and Cultures of Happiness: A Theoretical Conjecture on the Relationship between Consumption, Culture and Subjective Well-being at the National Level. Journal of Happiness Studies, 3, 23-36. https://doi.org/10. 1023/A:101568212

Boehm, J., Lyubomirsky, S., \& Sheldon, K. (2011). A Longitudinal Experimental Study Comparing the Effectiveness of Happiness-Enhancing Strategies in Anglo Americans and Asian Americans. Cognition and Emotion, 25(7), 1263-1272. https://doi.org/10. $1080 / 02699931.2010 .541227$

Brdar, I. \& Kashdan, T. (2009). Character Strengths and Well-being in Croatia: An Empirical Investigation of Structure and Correlates. Journal of Research in Personality, 44, 151-154. https://doi.org/10.1016/ j.jrp.2009.12.001

Buchanan, K. \& Bardi, A. (2010). Acts of Kindness and Acts of Novelty Affect Life Satisfaction. The Journal of Social Psychology, 150(3), 235-237. https://doi.org/10.1080/00224540903365554

Buschor, C., Proyer, R., \& Ruch, W. (2013). Self- and Peer-rated Character Strengths: How do they Relate to Satisfaction with Life and Orientations to Happiness? Journal of Positive Psychology, 8(2), 116-127. https://doi.org/10.1080/17439760.2012.75 8305

Castro, A. \& Consentino, A. (2016). The Relationships between Character Strengths and Life Fulfillment in the View of Lay-people in Argentina. Interdisciplinaria, 33(1), 65-80. https://doi.org/10. 16888/interd.2016.33.1.4

Cosentino, A. (2009). Evaluación de las virtudes y fortalezas humanas en población de habla hispana [Assessment of of the Character Strengths and Virtues in Spanish-Speaking Population]. Psicodebate, Psicología, Cultura y Sociedad, 10, 5371. https://doi.org/10.18682/pd.v10i0.388

Cosentino A. \& Castro, A. (2008). Inventario de Virtudes $y$ Fortalezas [Inventory of Virtues and Strengths]. Manuscrito inédito.

Dahlsgaard, K., Peterson, C., \& Seligman, M. (2005). Shared Virtue: The Convergence of Valued Human Strengths across Culture and History. Review of General Psychology, 9, 203-213. https://doi.org/10. 1037/1089-2680.9.3.203

Diener, E., Emmons, R., Larsen, R., \& Griffin, S. (1985). The Satisfaction with Life Scale. Journal of 
Personality Assessment, 49(1), 71-75. Lambert, N. M., Fincham, F. D., Stillman, T. F., \& Dean, https://doi.org/10.1207/s15327752jpa4901_13

Eguiluz, L. \& Plasencia, M. (2014). Las fortalezas humanas y la satisfacción con la vida [Human Strengths and Satisfaction with Life]. Psicoterapia y Familia, 27(1), 32-44.

Ferragut, M., Blanca, M., \& Ortiz-Tallo, M. (2014). Psychological Virtues during Adolescence: A Longitudinal Study of Gender Differences. European Journal of Developmental Psychology, 11(5), 521531. https://doi.org/10.1080/17405629.2013.876403

Gradišek, P. (2012). Character Strengths and Life Satisfaction of Slovenian In-service and Pre-service Teachers. CEPS Journal, 2(3), 167-180. https://ojs.cepsj.si/index.php/cepsj/article/view/379

Heintz, S., Kramm, C., \& Ruch, W. (2019). A Metaanalysis of Gender Differences in Character Strengths and Age, Nation, and Measure as Moderators. The Journal of Positive Psychology, 14(1),103-112. https://doi.org/10.1080/17439760.20 17.1414297

Hofstede, G. (2011). Dimensionalizing Cultures: The Hofstede Model in Context. Online Readings in Psychology and Culture, 2(1), 1-26. https://doi.org/ 10.9707/2307-0919.1014

Isaacowitz, D., Vaillant, G., \& Seligman, M. (2003). Strengths and Satisfaction across the Adult Lifespan. International Journal of Ageing and Human Development, 57(2), 181-201. https://doi.org/10.219 0/61EJ-LDYR-Q55N-UT6E

Kobau, R., Seligman, M. E., Peterson, C., Diener, E., Zack, M., Chapman, D., \& Thompson, W. (2011). Mental Health Promotion in Public Health: Perspectives and Strategies from Positive Psychology. American Journal of Public Health, 101(8), 1-9. https://doi.org/10.2105/AJPH.2010.300 083
L. R. (2009). More Gratitude, Less Materialism: The Mediating Role of Life Satisfaction. The Journal of Positive Psychology, 4(1), 32-42. https://doi.org/10. 1080/17439760802216311

Martínez-Martí, M. (2006). El estudio científico de las fortalezas trascendentales desde la psicología positiva [The Scientific Study of the Transcendental Strengths from the Positive Psychology Perspective]. Clínica y Salud, 17(3), 245-258.

Martínez-Martí, M. \& Ruch, W. (2014). Character Strengths and Well-being across the Lifespan: Data from a Representative Sample of German-speaking Adults Living in Switzerland. Frontiers in Psychology, 5, 1-10. https://doi.org/10.3389/fpsyg. 2014.01253

Padrós, F., Gutiérrez, C., \& Medina, M. (2015). Propiedades psicométricas de la Escala de Satisfacción con la Vida (SWLS) de Diener en población de Michoacán (México) [Psychometric Properties of Diener's Scale of Satisfaction with Life (SWLS) in a Mexican Population]. Avances en Psicología Latinoamericana, 33(2), 223-232. https://doi.org/10.12804/apl33.02.2015.04.

Park, N. \& Huebner, E. (2005). A Cross-Cultural Study of the Levels and Correlates of Life Satisfaction among Adolescents. Journal of Cross-Cultural Psychology, 36, 444-456. https://doi.org/10.1177/002202210527 5961

Park, N., Peterson, C., \& Ruch, W. (2009) Orientations to Happiness and Life Satisfaction in Twenty-Seven Nations. The Journal of Positive Psychology, 4(4), 273-279. https://doi.org/10.1080/174397609029336 90

Park, N., Peterson, C., \& Seligman, M. (2004). Strenghts of Character and Well-being. Journal of Social and Clinical Psychology, 23(5), 603-619.

Pavot, W. \& Diener, E. (1993). Review of the Satisfaction with Life Scale. Journal of Personality Assessment, 
5, 164-172. https://doi.org/10.1037//10403590.5.2.1 64

Peterson, C. \& Seligman, M. (2004). Character Strengths and Virtues. A Handbook and Classification. New York: Oxford University Press.

Peterson, C., Ruch, W., Beermann, U., Park, N., \& Seligman, M. (2007). Strengths of Character, Orientations to Happiness, and Life Satisfaction. The Journal of Positive Psychology, 2(3), 149-156. https://doi.org/10.1080/17439760701228938

Porto, A. \& Da-Fonseca, D. (2016). Asociaciones entre fortalezas del carácter y satisfacción con la vida: Un estudio con universitarios [Associations between Character Strengths and Life Satisfaction: A Study with College Students]. Acta Colombiana de Psicologia, 19(2), 90-96. http://dx.doi.org/10.14718/ ACP.2016.19.2.5

Proyer, R., Gander, F., Wyss, T., \& Ruch, W. (2011). The Relation of Character Strengths to Past, Present, and Future Life Satisfaction among German-Speaking Women. Applied Psychology: Health and wellbeing, 3(3), 370-384. https://doi.org/10.1111/j.1758 0854.2011.01060.x

Reyes, S. \& Ferragut, M. (2016). Fortalezas psicológicas y diferencias de sexo en adolescentes [Character
Strenghts and Sex Differences in Adolescents]. Escritos de Psicología, 9(3), 28-36. https://doi.org/10.5231/psy.writ.2016.2811

Seligman, M. (2011). Flourish: A Visionary New Understanding of Happiness and Well-being. New York: Simon and Schuster.

Seligman, M. \& Csikszentmihalyi, M. (2000). Positive psychology: An Introduction. American Psychologist, 55, 5-14. https://doi.org/10.1037//000 3-066X.55.1.5.

Seligman M., Steen, T., Park, N., \& Peterson, C. (2005). Positive Psychology Progress: Empirical Validation of Intervention. American Psychology, 60(5), 410$421 \mathrm{https}: / /$ doi.org/10.1037/0003-066X.60.5.410

Shimai, S., Otake, K., Park, N., Peterson, C., \& Seligman, M. (2006). Convergence of Character Strengths in American and Japanese Young Adults. Journal of Happiness Studies, 7(3), 311. https://doi.org/10.1007 /s10902-005-3647-7

Vela, J., Scott, G., Ikonomopoulos, J., González, S., \& Rodríguez, B. (2017) The Role of Character Strengths and Family Importance on Mexican American College Students' Life Satisfaction. Journal of Hispanic Higher Education, 16(3), 273285. https://doi.org/10.1177/1538192716628958 


\section{Appendix}

Character strengths and Life satisfaction correlation analysis. Male on the top section and female on the bottom section.

\begin{tabular}{|c|c|c|c|c|c|c|c|c|c|c|c|c|c|}
\hline & 1 & 2 & 3 & 4 & 5 & 6 & 7 & 8 & 9 & 10 & 11 & 12 & 13 \\
\hline Life Satisfaction & 1 & .068 & $.239^{*}$ & .005 & $.234^{*}$ & $.429^{* \star}$ & -.062 & $.261^{* \star}$ & $.256^{*}$ & .038 & $.499^{* *}$ & $.298^{* *}$ & $.225^{*}$ \\
\hline Apreciation of beauty & .066 & 1 & -.003 & -.119 & $.341^{\star *}$ & -.007 & .048 & $.223^{*}$ & .076 & .167 & .062 & -.039 & $.262^{* *}$ \\
\hline Fairness & .002 & .078 & 1 & .049 & .149 & $.382^{* *}$ & -.106 & $.324^{\star *}$ & $.202^{*}$ & .180 & $.277^{\star *}$ & $.462^{* *}$ & .106 \\
\hline Persistence & $.195^{* *}$ & -.042 & .102 & 1 & .053 & .055 & .136 & .059 & .068 & .187 & -.028 & .014 & -.030 \\
\hline Creativity & .087 & .123 & $.186^{* *}$ & $.156^{*}$ & 1 & .142 & .116 & $.310^{* *}$ & $.292^{* *}$ & $.398^{* *}$ & $.287^{* *}$ & .067 & -.001 \\
\hline Love & $.244^{\star *}$ & .072 & .035 & $.140^{*}$ & .112 & 1 & -.034 & $.205^{*}$ & $.264^{\star *}$ & -.007 & $.263^{\star *}$ & $.291^{\star *}$ & $.234^{*}$ \\
\hline 7. Self regulation & $.146^{*}$ & .061 & .076 & $.210^{* *}$ & $.145^{*}$ & -.015 & 1 & .031 & .050 & .161 & .085 & -.052 & -.136 \\
\hline Gratitude & $.321^{\star \star}$ & .058 & $.240^{* *}$ & $.129^{*}$ & $.241^{* \star}$ & $.140^{*}$ & $.127^{*}$ & 1 & $.252^{*}$ & .159 & $.262^{* *}$ & .151 & .156 \\
\hline 9. Leadership & $.147^{*}$ & .015 & .106 & $.190^{* *}$ & $.220^{* *}$ & $.185^{* *}$ & .085 & .122 & 1 & .011 & $.365^{* *}$ & $.201^{*}$ & .003 \\
\hline 10. Open mindedness & .081 & $.166^{*}$ & .083 & $.242^{\star *}$ & $.192^{* *}$ & .085 & $.293^{* *}$ & $.175^{* *}$ & $.203^{* *}$ & 1 & $.236^{*}$ & .127 & -.072 \\
\hline 11. Social Intelligence & $.168^{* *}$ & .085 & .022 & $.244^{* *}$ & $.191^{\star *}$ & $.186^{* *}$ & .071 & $.144^{*}$ & $.236^{\star *}$ & .003 & 1 & 192 & $.256^{\star}$ \\
\hline 12. Forgiveness & .041 & .084 & $.208^{\star *}$ & -.043 & .105 & .073 & $.152^{*}$ & $.133^{*}$ & .041 & .103 & .085 & 1 & $.228^{*}$ \\
\hline 13. Spirituality & $.206^{* *}$ & -.010 & .065 & $.128^{*}$ & .088 & $.164^{*}$ & .061 & $.290^{* *}$ & .111 & -.015 & .122 & $.147^{*}$ & 1 \\
\hline 14. Citizenship & .062 & .019 & .059 & .046 & -.050 & $.152^{*}$ & -.036 & .069 & $.198^{* *}$ & .070 & $.234^{* *}$ & .081 & .127 \\
\hline 15. Bravery & .041 & .059 & -.078 & $.130^{*}$ & $.228^{\star *}$ & .115 & .057 & .112 & $.196^{\star *}$ & .090 & $.297^{\star *}$ & -.045 & .041 \\
\hline 16. Curiosity & $.242^{* *}$ & $.138^{*}$ & .103 & $.153^{*}$ & $.308^{* *}$ & .103 & .059 & $.247^{\star *}$ & $.306^{* *}$ & $.256^{* *}$ & $.165^{\star}$ & .085 & .028 \\
\hline 17. Kindness & .022 & $.271^{* \star}$ & $.259^{* *}$ & .088 & $.198^{* *}$ & $.199^{* *}$ & .051 & $.327^{\star \star}$ & .105 & $.183^{* *}$ & .105 & $.165^{*}$ & $.186^{* \star}$ \\
\hline 18. Hope & $.205^{* *}$ & .008 & $.164^{*}$ & $.168^{* *}$ & $169^{* *}$ & $.182^{* *}$ & .120 & $.214^{\star *}$ & .120 & $.243^{* *}$ & .030 & $.147^{*}$ & .105 \\
\hline 19. Integrity & $.258^{\star *}$ & .011 & $.170^{\star *}$ & $.243^{\star *}$ & $.166^{*}$ & .089 & $.199^{\star *}$ & $.274^{* *}$ & $.174^{* *}$ & $.197^{\star *}$ & $.191^{* *}$ & .099 & $.152^{*}$ \\
\hline 20. Perspective & $.176^{* *}$ & .123 & $.217^{* *}$ & $.128^{*}$ & $.240^{* *}$ & .067 & $.225^{* *}$ & .126 & $.200^{* *}$ & $.261^{* *}$ & .120 & $.185^{* *}$ & -.060 \\
\hline 21. Prudence & .092 & .078 & $.203^{* *}$ & $.175^{\star \star}$ & .120 & .028 & $.186^{* *}$ & $.211^{\star *}$ & .006 & $.274^{* *}$ & .048 & $.205^{* *}$ & .094 \\
\hline 22. Humor & .097 & .032 & -.015 & .064 & $.149^{*}$ & $.137^{*}$ & -.020 & $.169^{*}$ & .127 & -.098 & .131 & $.139^{*}$ & $.173^{*}$ \\
\hline 23. Humility & .032 & -.087 & $.270^{\star *}$ & .095 & .030 & -.115 & .107 & $.201^{\star *}$ & -.104 & $.144^{*}$ & -.053 & .116 & .078 \\
\hline 24. Love for knowledge & -.102 & .014 & .096 & .013 & $.162^{*}$ & .045 & .048 & -.007 & .056 & $.218^{* *}$ & -.013 & .048 & -.096 \\
\hline 25. Zest & $.221^{\star \star}$ & .069 & .113 & $.349^{* *}$ & $296^{\star \star}$ & $.193^{* *}$ & $.191^{\star *}$ & $.331^{* *}$ & .125 & $.164^{*}$ & $.227^{* *}$ & .096 & $.157^{*}$ \\
\hline
\end{tabular}

Note. ${ }^{*} p<.05,{ }^{* *} p<.01$ 
Character strengths and Life satisfaction correlation analysis. Male on the top section and female on the bottom section (continued).

\begin{tabular}{|c|c|c|c|c|c|c|c|c|c|c|c|c|}
\hline & 14 & 15 & 16 & 17 & 18 & 19 & 20 & 21 & 22 & 23 & 24 & 25 \\
\hline Life Satisfaction & $.220^{*}$ & .111 & .177 & $.261^{* *}$ & $.350^{* *}$ & .102 & .172 & -.037 & $.327^{\star *}$ & -.128 & .114 & $.249^{*}$ \\
\hline Apreciation of beauty & -.051 & .149 & .153 & $.235^{*}$ & -.020 & $.219^{*}$ & .162 & -.044 & .029 & -.192 & .017 & .084 \\
\hline 3. Fairness & .120 & .010 & $.267^{\star *}$ & $.429^{\star *}$ & $.247^{*}$ & $.385^{\star *}$ & .163 & .097 & $.275^{*}$ & .164 & .069 & .191 \\
\hline 4. Persistence & .095 & .118 & .068 & .075 & .100 & .156 & .050 & .130 & -.126 & .171 & .140 & .100 \\
\hline 5. Creativity & .119 & $.282^{* \star}$ & $.302^{\star *}$ & $.364^{* *}$ & .144 & $.392^{* *}$ & $.308^{* *}$ & -.033 & $.306^{* *}$ & $-.232^{*}$ & .201 & .212 \\
\hline 6. Love & $.275^{\star *}$ & -.012 & .184 & $.396^{\star *}$ & $.330^{* *}$ & $.283^{* *}$ & .149 & .084 & $.310^{\star *}$ & .084 & .006 & .189 \\
\hline 7. Self regulation & .036 & 130 & .059 & .028 & .071 & 193 & .096 & .181 & -.068 & -.052 & .158 & .157 \\
\hline 8. Gratitude & .161 & $.246^{\star}$ & $.407^{* *}$ & $.463^{* *}$ & .190 & .176 & $.319^{* *}$ & .009 & $.266^{*}$ & -.077 & -.020 & $.525^{* *}$ \\
\hline 9. Leadership & $.334^{* *}$ & .151 & $.205^{*}$ & $.269^{* *}$ & .185 & 109 & $.276^{* *}$ & -.124 & .170 & -.200 & .164 & $.247^{*}$ \\
\hline 10. Open mindedness & -.056 & $.323^{* *}$ & $.311^{* \star}$ & $.356^{* *}$ & .098 & $.357^{* *}$ & $.307^{* *}$ & .170 & .021 & .127 & $.285^{* \star}$ & .095 \\
\hline 11. Social Intelligence & $.330^{\star *}$ & $.333^{* *}$ & $.210^{*}$ & $.472^{* \star}$ & $.370^{* *}$ & $.250^{*}$ & $.387^{\star \star}$ & -.185 & $.330^{\star *}$ & -.204 & .101 & .207 \\
\hline 12. Forgiveness & .012 & -.012 & .121 & $.208^{*}$ & $.380^{* *}$ & 129 & $.312^{* *}$ & .157 & .024 & .009 & .178 & $.232^{\star}$ \\
\hline 13. Spirituality & .099 & .084 & .026 & $.264^{* *}$ & $.218^{*}$ & -.024 & .195 & .085 & .044 & -.037 & -.119 & .008 \\
\hline 14. Citizenship & 1 & -.036 & .068 & .151 & .123 & -.001 & .075 & .062 & $.386^{\star *}$ & $-.287^{\star *}$ & $-.241^{*}$ & .092 \\
\hline 15. Bravery & .027 & 1 & $.197^{*}$ & $.326^{* *}$ & -.082 & .188 & $.350^{* *}$ & -.115 & .168 & -.151 & $.374^{\star \star}$ & .178 \\
\hline 16. Curiosity & .066 & $.225^{\star *}$ & 1 & $.346^{* *}$ & .164 & $.261^{\star *}$ & $.302^{* \star}$ & .078 & $.301^{\star *}$ & -.050 & .058 & $.376^{\star *}$ \\
\hline 17. Kindness & .096 & .010 & $.255^{\star *}$ & 1 & $.298^{\star *}$ & $.335^{\star *}$ & $.459^{* *}$ & .005 & $.352^{* *}$ & -.007 & .070 & $.296^{* *}$ \\
\hline 18. Hope & $.143^{*}$ & .068 & $.246^{\star *}$ & .078 & 1 & .156 & $.246^{\star}$ & .079 & $.253^{*}$ & .148 & .062 & $.237^{*}$ \\
\hline 19. Integrity & .123 & $.154^{*}$ & $.186^{\star *}$ & $.162^{*}$ & $.265^{\star *}$ & 1 & $.243^{*}$ & .036 & .122 & -.002 & $.314^{\star \star}$ & $.322^{\star *}$ \\
\hline 20. Perspective & -.104 & $.136^{*}$ & $.380^{* *}$ & $.268^{* *}$ & $.169^{* *}$ & $.258^{* *}$ & 1 & .064 & .157 & -.078 & .110 & $.297^{* *}$ \\
\hline 21. Prudence & .089 & .083 & $.182^{* *}$ & $.163^{\star}$ & $.220^{* *}$ & $.272^{* *}$ & $.208^{* *}$ & 1 & -.135 & .094 & .073 & $.287^{* *}$ \\
\hline 22. Humor & $.152^{*}$ & -.007 & .092 & .116 & .071 & -.001 & .047 & -.113 & 1 & $-.244^{*}$ & .056 & .140 \\
\hline 23. Humility & $-.141^{*}$ & -.110 & .070 & 110 & .040 & $.207^{* *}$ & .062 & $.265^{\star \star}$ & -.081 & 1 & .034 & -.133 \\
\hline 24. Love for knowledge & .031 & .107 & $.254^{\star *}$ & .064 & .126 & -.043 & .042 & $.147^{*}$ & .056 & .114 & 1 & .148 \\
\hline 25. Zest & $.209^{* *}$ & $.193^{* *}$ & $.292^{* \star}$ & $.283^{* *}$ & $237^{\star *}$ & $.270^{\star *}$ & $192^{* *}$ & .128 & $.202^{\star *}$ & .051 & .085 & 1 \\
\hline
\end{tabular}

Note. ${ }^{*} p<.05,{ }^{* *} p<.01$ 